\title{
PENGETAHUAN MASYARAKAT TENTANG PROSEDUR BANTUAN HIDUP DASAR PADA KORBAN KECELAKAAN LALU LINTAS
}

\author{
Rudi Kurniawan $^{1}$, Nur Aef Muttaqin ${ }^{2}$, Elis Roslianti ${ }^{3}$, \\ ${ }^{1,2,3}$ STIKes Muhammadiyah Ciamis
}

e-mail:akhrud2008@yahoo.com

\begin{abstract}
ABSTRAK
Latar belakang: angka kecelakaan lalu lintas di Kabupaten Ciamismengalami peningkatan dalam dua tahun terakhir,pada tahun 2015 sebanyak 324 kejadian yang menyebabkan 117 orang meninggal. Pada tahun 2016 sebanyak 340 kejadian, yang mengakibatkan 154 orang meninggal dunia.Kejadian ini bisa dicegah dengan bantuan hidup dasar. Hasil studi pendahuluan melalui wawancara terhadap warga menunjukkanbeberapa orang tidak mengetahui prosedur bantuan hidup dasar pada korban kecelakaan lalu lintas. Bantuan hidup dasar kepada korban berupa pertolongan pertama seharusnya juga dimiliki oleh seluruh lapisan masyarakat, karena yang terlebih dahulu ada di tempat kejadian ketika terjadi kecelakaan adalah masyarakat umum. Tujuan: dari penelitian ini adalah untuk mengetahui pengetahuan masyarakat umum tentang prosedur bantuan hidup dasar pada korban kecelakaan lalu lintas. Metode: penelitian ini menggunakan deksriptif dengan jumlah populasi sebanyak 296 orang. Teknik pengambilan sampel menggunakan Proporsional Random Sampling sebanyak 75 orang. Hasil:penelitian didapat bahwa pengetahuan masyarakat tentang pengetahuan bantuan hidup dasar pada korban kecelakaan lalu lintas dikategorikan kurang yaitu pengetahuannya baik sebanyak 3 responden (4,0\%), pengetahuannya cukup sebanyak 18 responden $(24,0 \%)$, dan yang pengetahuannya kurang sebanyak 54 responden (72\%). Simpulan:bahwa pengetahuan masyarakat tentang prosedur bantuan hidup dasar pada korban kecelakaan lalu lintas sebagian besar menunjukkan pengetahuan kurang $(72 \%)$.
\end{abstract}

Kata kunci: Pengetahuan, Bantuan Hidup Dasar, Pertolongan Pertama

\section{COMMUNITY KNOWLEDGE ABOUT BASIC LIVING ASSISTANCE PROCEDURES ON TRAFFIC ACCIDENT VICTIMS}

\begin{abstract}
Introduction:The impact of traffic accidents is a terrible scourge that occurs in most countries. In addition to basic life support health workers to victims, they should also be owned by all levels of society, because those who were first at the scene when the accident occurred were the general public. The purpose of this study was to find out the general knowledge of the Basic Life Assistance Procedure for victims of traffic accidents. Method: this study used descriptive with a population of 296 people. The sampling technique used Proportional Random Sampling of 75 people. Result: The result showed that public knowledge about Basic Living Rock knowledge in victims of traffic accidents was categorized as less, namely good knowledge as many as 3 respondents $(4.0 \%)$, sufficient knowledge as much as 18 respondents $(24.0 \%)$, and whose knowledge was less than 54 respondents $(72 \%)$ of a total sample of 75 people. Conclusions: that Community Knowledge About Basic Life Assistance Procedures for Traffic Accident Victims, there is an illustration that more people have less knowledge than adequate or good.
\end{abstract}

Keywords:Knowledge, Basic Living Unit, First Aid

Jurnal SMART Keperawatan Sekolah Tinggi Ilmu Kesehatan (STIKes) Karya Husada Semarang www.stikesyahoedsmg.ac.id/ojs/index.php/sjkp (perawat) 


\section{Pendahuluan}

Kecelakaan lalu lintas adalah masalah global(Gebru, 2017) dan kecelakaan lalu lintas merupakan salah satu masalah kesehatan yang tidak tergolong dalam penyakit menular (Hidayati, 2016), karena kecelakaan lalu lintas merupakan salah satu masalah kesehatan masyaakat yang mempengaruhi sektor kehidupan (Buamona, 2017).Selain faktor korban kecelakaan yang meninggal langsung di tempat kejadian, faktor lain yang juga dapat menyebabkan korban kecelakaan meninggal dunia adalah juga faktor pertolongan pertama pada korban kecelakaan terutama pada korban yang mengalami trauma, dimana hal ini sangat penting untuk korban kecelakan (Pro Emergency , 2014).Menurut Rinaldi (2017), mengatakan bahwa kecelakaan lalu lintas dapat mengakibatkan seseorang mengalami kerugian dalam bentuk psikologis seperti trauma.

American college Of Surgeon (ACS) menguraikan bahwa kematian karena trauma dapat terjadi sesaat setelah kejadian, dalam perjalanan ke ruamh sakit, saat di rumah sakit atau setelah pulang dari rumah sakit, juga menguraikan distribusi kematian akibat trauma yang dikenal dengan trimodal death, distribusi yang terbagi dalam beberapa puncak kematian akibat trauma. Puncak pertama yaitu 50\% kematian akibat trauma terjadi beberapa detik atau beberapa menit setelah kejadian. Puncak kedua yaitu 35\% kematian terjadi dalam satu sampai dua jam setelah trauma. Puncak ketiga yaitu $15 \%$ kematian terjadi beberapa hari atau beberapa minggu setelah kejadian (Pro Emergency , 2014).

Pertolongan Pertama adalah "pertolongan dan perawatan awal atau sementara pada korban kecelakaan sebelum korban diberikan pertolongan dan perawatan dari tenaga medis dan dokter" (Campbell, 2013). Sedangkan menurut Howard (2010), Pertolongan pertama adalah "pertolongan sementara yang diberikan kepada seseorang yang menderita sakit atau kecelakaan sebelum mendapat pertolongan dari dokter". Korban kecelakaan dapat semakin buruk atau berujung pada kematian jika tidak ditangani dengan cepat pada satu jam pertama (Ambarika, 2017). Menurut AHA (American Heart Associations) (2015), masyarakat dalam bidang keperawatan kegawatdaruratan dibedakan menjadi 2, yaitu masyarakat awam dan masyarakat tenaga medis (Pro Emergency, 2014a).

Menurut Frame (2010) bahwa keterampilan bantuan hidup dasar dapat diajarkan kepada siapa saja. Setiap orang dewasa seharusnya memiliki keterampilan bantuan hidup dasar, bahkan anak-anak juga dapat diajarkan sesuai kapasitasnya. Bantuan hidup dasar 
seharusnya dimiliki oleh seluruh lapisan masyarakat, baik itu tenaga kesahatan maupun masyarakat yang bukan merupakan tenaga kesehatan. Karena pada saat kejadian, tidak langsung tenaga kesahatan yang berada di tempat kejadian, karena yang terlebih dahulu ada di tempat kejadian adalah masyarakat umum. Apabila masyarakat umum yang tidak mengetahui bagaimana langkah untuk melakukan bantuan hidup dasar kepada korban maka akan mengakibatkan hal yang fatal untuk korban (Pro Emergency, 2014).

American Academy of Pediatric juga menjabarkan bahwa "semua lapisan masyarakat seharusnya diajarkan tentang bantuan hidup dasar terlebih bagi para pekerja yang berkaitan dengan pemberian pertolongan keselamatan" (Howard, 2010).Dari hasil studi pendahuluan dengan wawancara sederhana yang di lakukan oleh penulis pada tanggal 13 Maret 2017 pada masyarakat yang tinggal di sekitar jalan raya di Wilayah Kerja Polisi Sektor Ciamis. Penulis mewawancarai 10 orang masyarakat umum, hasil wawancara kesepuluh orang tersebut mereka tidak mengetahui prosedur bantuan hidup dasar pada korban kecelakaan lalu lintas.

Masyarakat menjadi saksi dan penolong pertama yang ada di tempat kejadian setiap ada kecelakaan lalu lintas.Penelitian ini dilakukan di Wilayah Kerja Polisi Sektor Ciamis. Menurut IPDA Asep S. Kepala Lakalantas Polisi Sektor Ciamis, Ciamis merupakan wilayah dengan angka kejadian kecelakaan lalu lintas dengan angka kejadian sebanyak 62 kejadian pada 2015 dan 71 kejadian di tahun 2016. Kecelakaan lalu lintas terjadi dari mulai daerah Kertasari sampai dengan daerah Cimari. Seorang narasumber yang diwawancarai mengatakan bahwa beberapa tahun yang lalu ada masyarakat yang menolong korban kecelakaan, penolong tidak tepat melakukan tindakan memindahkan korban sehingga korban sakit parah.

Berdasarkan latar belakang tersebut maka penulis tertarik untuk meneliti Pengetahuan Masyarakat Tentang Prosedur Bantuan Hidup Dasar Pada Korban Kecelakaan Lalu Lintas.

\section{Metode Penelitian}

Penelitian ini mengunakan analisa univariat untuk mengetahui gambaran pengetahuan masyarakat tentang bantuan hidup dasar pada korban kecelakaan lalu lintas. Jenis penelitian yang digunakan adalah deksriptif. Populasi dalam penelitian ini masyarakat yang berdomisili tetap dan sampai rumah kedua dari jalan raya di Daerah Kertasari dan 
Daerah Cimari, yaitu dari Jalan Raya Ahmad Yani dan Jalan Raya Cimari, dengan jumlah populasi sebanyak 296 orang. Teknik pengambilan sampel menggunakan Proporsional Random Sampling yaitu sebagian dalam populasi yang dapat mewakili target keseluruhan sebanyak 75 orang. Penelitian ini menggunakan instrumen penelitian berupa lembar wawancara untuk variabel, lembar wawancara telah disusun atau di buat disesuaikan dengan kebutuhan data yang di perlukan agar sesuai dengan kebutuhan penelitian. Cara pemberian skor dalam penelitian ini adalah apabila responden menjawab dengan benar maka mendapatkan nilai 1 , dan jika responden menjawab salah maka mendapatkan nilai 0 .

\section{Hasil Penelitian}

Berdasarkan hasil penelitian yang di lakukan pada tanggal 14 Juni sampai dengan 17 Juni 2017 mengenai Pengetahuan Masyarakat Tentang Prosedur Bantuan Hidup Dasar Pada Korban Kecelakaan Lalu Lintas Di Wilayah Kerja Polisi Sektor Ciamis Kabupaten Ciamis Tahun 2017, sebagai berikut

\section{Tabel 1}

\section{Distribusi Pengetahuan Masyarakat Tentang Prosedur Bantuan Hidup Dasar Pada Korban Kecelakaan Lalu Lintas}

\begin{tabular}{lcc}
\hline Pengetahuan & $\begin{array}{c}\text { Frekuensi } \\
\text { (orang) }\end{array}$ & Presentase \%) \\
\hline Baik & 3 & 4 \\
Cukup & 18 & 24 \\
Kurang & 54 & 72 \\
Jumlah & $\mathbf{7 5}$ & $\mathbf{1 0 0 \%}$ \\
\hline
\end{tabular}

Berdasarkan Tabel. 1 diketahui frekuensi Pengetahuan Masyarakat Tentang Prosedur Bantuan Hidup Dasar Pada Korban Kecelakaan Lalu Lintas Di Wilayah Kerja Polisi Sektor Ciamis Kabupaten Ciamis Tahun 2017 dengan pengetahuannya baik sebanyak 4,0\%, pengetahuannya cukup sebanyak $24,0 \%$, dan yang pengetahuannya kurang $72 \%$. dari total sampel 75 orang. 


\section{Tabel .2}

Distribusi Frekuensi Pengetahuan Masyarakat Tentang Prinsip Aman Diri Sendiri, Aman Korban Dan Aman Lingkungan

\begin{tabular}{lcc}
\hline Pengetahuan & Frekuensi (orang) & Presentase (\%) \\
\hline Baik & 20 & 26,6 \\
Cukup & 29 & 38,7 \\
Kurang & 26 & 34,7 \\
Jumlah & $\mathbf{7 5}$ & $\mathbf{1 0 0 \%}$ \\
\hline
\end{tabular}

Tabel. 2 menyatakan frekuensi Pengetahuan Masyarakat Tentang Prinsip Aman Diri Sendiri, Aman Korban Dan Aman Lingkungan, yaitu sebanyak 20 orang (26,6\%) termasuk pengetahuannya baik, sebanyak 29 orang $(38,7 \%)$ pengetahuannya cukup dan sebanyak 26 orang $(34,7 \%)$ pengetahuannya kurang.

Tabel 3

Distribusi Frekuensi Pengetahuan Tentang Mengecek Respon Korban

\begin{tabular}{lcc}
\hline Pengetahuan & Frekuensi (orang) & Presentase (\%) \\
\hline Baik & 4 & 5,3 \\
Cukup & 36 & 48,0 \\
Kurang & 35 & 46,7 \\
Jumlah & $\mathbf{7 5}$ & $\mathbf{1 0 0 \%}$ \\
\hline
\end{tabular}

Pada Tabel. 3 diketahui frekuensi pengetahuan tentang tindakan mengecek respon korban, yaitu sebanyak 4 orang $(5,3 \%)$ termasuk pengetahuannya baik, sebanyak 36 orang $(48,0 \%)$ pengetahuannya cukup dan sebanyak 35 orang (46,7\%) pengetahuannya kurang

Tabel 4

Distribusi Frekuensi Pengetahuan Tentang Meminta Tolong ke Pusat Komunikasi Gawat Darurat

\begin{tabular}{lcc}
\hline Pengetahuan & Frekuensi (orang & Presentase (\%) \\
\hline Baik & 8 & 10,7 \\
Cukup & 7 & 9,3 \\
Kurang & 60 & 80 \\
Jumlah & $\mathbf{7 5}$ & $\mathbf{1 0 0 \%}$ \\
\hline
\end{tabular}

Frekuensi kejadian flebitis pada pemasangan infus dilihat dari faktor jenis cairan sebagian besar yaitu sebanyak 8 orang $(.10,7 \%)$ termasuk pengetahuannya baik,sebanyak 7 orang 
$(9,3 \%)$ pengetahuannya cukup dan sebanyak 60 orang (80\%) pengetahuannya kurang dapat dilihat pada Tabel.4

Tabel 5

Distribusi Frekuensi Pengetahuan Tentang Membebaskan Jalan Napas Secara Manual

\begin{tabular}{lcc}
\hline Pengetahuan & Frekuensi (orang) & Presentase (\%) \\
\hline Baik & 12 & 16,0 \\
Cukup & 14 & 18,7 \\
Kurang & 49 & 65,3 \\
Jumlah & $\mathbf{7 5}$ & $\mathbf{1 0 0 \%}$ \\
\hline
\end{tabular}

Pada tabel 5 diketahui frekuensi pengetahuan tentang membebaskan jalan napas secara manual yaitu sebanyak 12 orang (16,0\%) termasuk pengetahuannya baik, sebanyak 14 orang $(18,7 \%)$ pengetahuannya cukup dan sebanyak 49 orang $(65,3 \%)$ pengetahuannya kurang.

Tabel 6.

Distribusi Frekuensi Pengetahuan Tentang Memberikan Napas Buatan Pada Pasien Henti Napas.

\begin{tabular}{lcc}
\hline Pengetahuan & Frekuensi (orang) & Presentase (\%) \\
\hline Baik & 8 & 10,7 \\
Cukup & 15 & 20,0 \\
Kurang & 52 & 69,3 \\
Jumlah & $\mathbf{7 5}$ & $\mathbf{1 0 0 \%}$ \\
\hline
\end{tabular}

Berdasarkan tabel 6 diketahui frekuensi pengetahuan tentang memberikan napas buatan pada pasien yang henti napas yaitu sebanyak 8 orang $(10,7 \%)$ termasuk pengetahuannya baik, sebanyak 15 orang $(20,0 \%)$ pengetahuannya cukup dan sebanyak 52 orang $(69,3 \%)$ pengetahuannya kurang.

Tabel 7

Distribusi Frekuensi Pengetahuan Tentang Menghentikan Perdarahan, Melakukan Pembidaian, Mengatasi Syok Dengan Melakukan Pijat Jantung Luar.

\begin{tabular}{lcc}
\hline Pengetahuan & Frekuensi (orang) & Presentase (\%) \\
\hline Baik & 3 & 12,0 \\
Cukup & 13 & 17,3 \\
Kurang & 53 & 70,7 \\
Jumlah & $\mathbf{7 5}$ & $\mathbf{1 0 0 \%}$ \\
\hline
\end{tabular}


Berdasarkan tabel.7 diketahui frekuensi pengetahuan tentang menghentikan perdarhan, melakukan pembidaian, mengatasi syok dengan melakukan pijat jantung luar yaitu sebanyak 9 orang $(12,0 \%)$ termasuk pengetahuannya baik, sebanyak 13 orang $(17,3 \%)$ pengetahuannya cukup dan sebanyak 53 orang (70,7\%) pengetahuannya kurang.

Tabel 8

DistribusiFrekuensiPengetahuan Tentang Mengangkat Serta Memindahkan Korban Dengan
Benar Serta MelakukanImobilisasi Pada Kecurigaan Patah Tulang Leher Dan Patah Tulang
Belakang.

\begin{tabular}{llc}
\hline \multicolumn{2}{l}{ PengetahuanFrekuensi (orang)Presentase (\%) } \\
\hline Baik & 6 & 8,0 \\
Cukup & 32 & 42,7 \\
Kurang & 37 & 49,3 \\
Jumlah & $\mathbf{7 5}$ & $\mathbf{1 0 0 \%}$ \\
\hline
\end{tabular}

Berdasarkan Tabel. 8 diketahui frekuensi pengetahuan tentang mengangkat serta memindahkan korban dengan benar serta melakukan imobilisasi pada kecurigaan patah tulang leher dan tulang belakang yaitu sebanyak 6 orang $(8,0 \%)$ termasuk pengetahuannya baik, sebanyak 32 orang $(42,7 \%)$ pengetahuannya cukup dan sebanyak 37 orang $(49,3 \%)$ pengetahuannya kurang.

\section{Pembahasan}

Frame (2010) menuturkan Bantuan Hidup Dasar (BHD) merupakan usaha sederhana yang dilakukan untuk mengatasi keadaan yang mengancam nyawa seseorang sehingga dapat mempertahankan hidupnya untuk sementara.

Hasil penelitian tentang prinsip aman diri sendiri, aman korban dan aman lingkungan menunjukan masih kurangnya pengetahuan masyrakat tentang melakukan prinsip aman diri sendiri, aman korban dan aman lingkungan. Sesuaidenganteoribahwa prinsip 3A (aman penolong, pasien, lingkungan) harus senantiasa diperhatikan untuk keamanan penolong dan korban pada saat pemberian pertolongan pada korban kecelakaan (AHA (2013) dalam Pro Emergency, 2014).

Hasil penelitian ini tentang pengetahuan tentang mengecek respon korbanmenunjukan kurangnya pengetahuan masyrakat tentang melakukan pemeriksaan kesadaran korban, sesuai dengan kejadian dilapangan penolong jarang melakukan pemeriksaan kesadaran 
korban. Sesuai dengan teori bahwa menilai kesadaran di awal penilaian dilakukan dengan cepat dan tepat, dimana hal ini untuk segera melakukan rencana tindakan pertolongan bagi korban. Cek kesadaran di awal ini untuk mengetahui sadar atau tidaknya korban (AHA (2013) dalam Pro Emergency, 2014).

Hasil penelitian tentang pengetahuan meminta tolong ke pusat komunikasi gawat darurat menunjukan bahwa masyarakat masih belum mengetahui harus kemana melaporkan terlebih dahulu apabila ada kecelakaan, sesuai dengan teori bahwa mengaktifkan atau meminta bantuan ke pusat komunikasi gawat darurat seperti rumah sakit. masyarakat seharusnya mengetahui nomor panggilan darurat. Di Indonesia sendiri terdapat tiga nomor panggilan darurat, 118 unntuk ambulance gawat darurat, 113 untuk pemadam kebakaran dan 110 untuk kepolisian (AHA (2013) dalam Pro Emergency , 2014a).

Hasil penelitian pengetahuan tentang membebaskan jalan napas secara manual menunjakan bahwa masyarakat masih belum mengetahui korban yang harus diberikan napas buatan. Hasil penelitian pengetahuan tentang memberikan napas buatan pada pasien yang henti napas.menunjakan bahwa masyarakat masih belum mengetahui korban yang harus diberikan napas buatan. Sesuai dengan teori bahwa pendarahan berat maupun ringan jika tidak segera dirawat bisa berakibat fatal. Bila pendarahan terjadi, penting bagi penolong untuk menghentikannya secepat mungkin, ada dua jenis pendarahan yaitu pendarahan luar (pendarahan dari luka) dan pendarahan dalam (pendarahan di dalam tubuh). pembidaian sendiri bisa di lakukan dengan alat alat sederhana yang ada di sekitar kita, seperti kain, selendang, jarik, bantal, kayu atau alat bidai khusus bila berada di fasilitas kesehatan untuk menopang tulang yang patah agar posisnya tidak berubah dan pijat jantung luar usaha ini untuk memaksa jantung memompakan darah ke seluruh tubuh, pijat jantung dilakukan pada korban dengan nadi karotis (nadi pada leher) yang tidak teraba (AHA (2013) dalam Pro Emergency, 2014).

Sesuai dengan teori bahwa jangan memindahkan atau mengankat korban yang terluka kecuali ada bahaya api, lalu-lintas, asap beracun atau hal lain yang membahayakan korban maupun penolong karena apabila korban dicurigai patah tulan leher atau tulang elakang akan membahayakan korban bahkan bisa menyebabkan kematian apabila pemindahan korban salah dalam cara mengangkatnya (AHA (2013) dalam Pro Emergency, 2014a). 


\section{Kesimpulan}

Berdasarkan hasil penelitian dan pembahasan dapat disimpulkan bahwaPengetahuan Masyarakat Tentang Prosedur Bantuan Hidup Dasar Pada Korban Kecelakaan Lalu LintasDi Wilayah Kerja Polisi Sektor Ciamis Kabupaten CiamisTahun 2017 denganpengetahuannya baik sebanyak $4,0 \%$, pengetahuannya cukup sebanyak $24,0 \%$, dan yang pengetahuannya kurang $72 \%$. dari total sampel 75 orang.

\section{Daftar Pustaka}

Ambarika, R. (2017). Efektifitas Simulasi Prehospital Care Terhadap Self efficacy Masyarakat Awam Dalam Memberikan Pertolongan Pertama Korban Kecelakaan Lalu Lintas. Jurnal Keperawatan UMM. Volume 8. No 1. P.25.

Buamona, S., dkk. (2017). Pengaruh Pendidikan Kesehatan Terhadap Tingkat Pengetahuan Bantuan Hidup Dasar (BHD) Pada Kecelakaan Lalu Lintas PadaSiswa SMA Negeri 1 Sanana Kabupaten Kepulawan Sula Maluku Utara. E-Jurnal keperawatan. Volume 5. No 1. P.1.

Campbell, JE. (2013). Basic Trauma Life Support. American College Of Emergency Physician. Fourth Edition.

Frame. (2010). National Association of Emergency Medical Techinicians. Pre-Hospital Trauma Life Support. Fourth Edition.

Gebru, Micheale Kihishen. (2017). Road Traffic Accident: Human Security Perspective. International Journal of Peace and Develovment Studies Vol. 8(2) p, 15- 24. DOI: 10.5897/IJPDS2016.0289.

Guidelines. (2015). Pedoman AHA (American Heart Association) untuk CPR dan ECC.

Hidayati, Annisa dan Lucia Yovita Hendrati. (2016). Analisis Risiko Kecelakaan Lalu Lintas Berdasar Pengetahuan, Penggunaan Jalur, dan Kecepatan Berkendara. Jurnal Berkala Epidemiologi Vol. 04 No. 02 (p. 257-287).

Howard, P. K. (2010). Emergency Nursing Princip and Practice. Sixth Edition.

Notoatmodjo. (2010). Metodologi Peneltian Kesehatan Edisi Revisi. Jakarta : PT Rineka cipta.

Pro Emergency. (2014 ). Basic Trauma Life Support for Nurse. Jakarta.

Rinaldi, F. R., dan Achmad Mujab Masykur. (2017). Pengalaman Kecelakaan Lalu lintas Berat. Jurnal Empati Vol. 6(1) (p. 164- 172). 